\title{
Silencing expression of the NANOG gene and changes in migration and metastasis of urinary bladder cancer cells
}

Natalia Gawlik-Rzemieniewska, Anna Galilejczyk, Michał Krawczyk, Ilona Bednarek

School of Pharmacy with the Division of Laboratory Medicine in Sosnowiec, Department of Biotechnology and Genetic Engineering, Medical University of Silesia, Katowice, Poland

Submitted: 23 September 2014

Accepted: 1 January 2015

Arch Med Sci 2016; 12, 4: 889-897

DOI: $10.5114 /$ aoms.2015.55368

Copyright @ 2015 Termedia \& Banach

\section{Abstract}

Introduction: It has been proved that expression of the NANOG gene is observed not only in embryonic-derived malignancies, but also in breast cancer, ovarian cancer, cervix cancer and bladder cancer. NANOG overexpression is correlated with high activity of MMP-2 and MMP-9. The aim of the study was to evaluate the changes in the malignant phenotype of T24 bladder cancer cells with modulated expression of the NANOG gene.

Material and methods: Human urinary bladder cancer cells T24 (HTB-4) were cultivated under standard conditions. Transfection of the cells with silencing constructions was performed with the application of Lipofectamine 2000 (Invitrogen) reagent. Evaluation of changes in the expression level of individual genes was performed using qRTPCR. Changes in the protein level were evaluated using the Human ELISA Kit (Abcam). The invasion capability of transfected cells was tested using Matrigel Invasion Chambers (BD Biosciences). The changes in cell migration were assessed with a wound-healing assay. Results: The qRTPCR evaluation showed that silencing the NANOG gene in T24 cells led to the decrease of mRNA for the MMP-2 gene to the level of $62.4 \%$ and the MMP-9 gene to the level of $76 \%$. The cells with modulated expression of the NANOG gene migrated slower in the Matrigel invasion assay and in the wound-healing assay. The immunoenzymatic test showed a decrease in the protein level of MMP-9.

Conclusions: The transcriptional activity of the NANOG gene might be connected with some aspects of bladder cancer cell metastasis in vitro and has an influence on MMP-2 and MMP-9 expression levels.

Key words: RNAi, MMP-2, MMP-9, TIMP-1, shRNA.

\author{
Corresponding author: \\ Natalia Gawlik- \\ Rzemieniewska \\ School of Pharmacy \\ with the Division of \\ Laboratory Medicine \\ Department \\ of Biotechnology \\ and Genetic Engineering \\ Medical University \\ of Silesia in Katowice \\ 8 Jedności St \\ 41-200 Sosnowiec, Poland \\ Phone: +48 323641275 \\ E-mail: natalia.gawlik- \\ rzemieniewska@med.sum. \\ edu.pl
}

\section{Introduction}

Bladder cancer is one of the major cancers in Poland. The estimated incidence of urinary bladder cancer in men in Poland in 2011 and 2012 is 4882 , while the estimated number of deaths is 2593 . In 2010, urinary bladder cancer was the fourth most frequently registered malignant cancer $(7 \%)$ and held fifth place of cancer caused deaths (4.8\%) within men [1]. What is more, an increase in the number of bladder cancer cases is predicted in the year 2019 in both sexes [2].

The characteristic properties which distinguish normal tissues from malignant ones are attributed to cancer stem cells (CSCs). These are cells within the tumor which have abilities to self-renew and to create the heterogeneous lineage of cells which constitute the tumor [3-5]. It 
is thought that embryonic stem cells (ECS) and CSCs have some common phenotypic properties. Both types of cells are characterized by intensive growth and high expression of telomerase, which is responsible for cell immortality.

NANOG is a transcription factor which is involved in the self-renewal of ECs. NANOG was first described as an important transcription factor in ECs, which both activates the repressors and suppresses the activators of differentiation. Its name derives from Tìr nan Òg, the mythical Celtic land of the ever young $[6,7]$. The NANOG gene is located on chromosome 12 at position $12 \mathrm{p} 13.31$. On this chromosome, there is also located a NANOG pseudogene, NANOGP1, which is $97 \%$ identical with the paternal gene. However, they are spliced in a different way. There are also ten other NANOG pseudogenes, which are developed as a result of mRNA retrotransposition, and they are characterized by the absence of introns and the 5' promoter sequences. NANOGP1, P2, P4, P7, P8, P9 and P10 show $90 \%$ of homology to NANOG, and NANOGP5 shows $85 \%$ homology to this parental gene $[8,9]$. NANOG, together with octamer-binding transcription factor 4 (OCT4) and sex-determining region $Y$ HMG-box 2 (SOX2), is responsible for maintaining ECs in the undifferentiated state. mRNA for the NANOG gene is possible to detect only in the epiblast of the implanting blastocyst. A small amount of NANOG mRNA is also present in germ cells, but it is not observed in somatic cells of adult organisms [8, 10, 11].

Although ECs and CSCs share common properties, there are also some differences between them. Both types of cells are able to self-renew, but ECs set off (are distinguished by) differentiation, and CSCs set off proliferation [5, 12]. It has been found that the NANOG gene and some of its pseudogenes (NANOGP2, NANOGP7, NANOGP8) are expressed in several cancer cell lines, including urinary bladder cancers and carcinomas [13-17].

The most widely used treatment for malignancies, including urinary bladder cancer, is chemotherapy. The efficiency of chemotherapy is, however, surprisingly low. The 5-year survival rate for patients with regional and distant metastases is below $50 \%$ and $10 \%$, respectively [18]. It is known that the system of gene expression regulation is an essential element of correct operation between cells and the whole organism. Disturbances in the balance between the expression levels of individual genes can lead to the process of carcinogenesis. Inhibition of overexpressed genes responsible for this process could limit the development of a malignant phenotype.

The advanced stages of malignancies are highly resistant to conventional treatment. Therefore, there is a demand for developing alternative anti- cancer therapies and better understanding of the mechanisms responsible for the malignant phenotypes. A very effective method of gene expression regulation used worldwide is RNA interference (RNAi). For posttranscriptional gene silencing, the RNAi phenomenon uses double-stranded RNA molecules called short interfering RNA (siRNA). A very effective and beneficial technique is to express SiRNA in the form of short hairpin RNA (shRNA) directly in the target cell. Using the RNAi method it was possible to discover the role of many genes arranged in the process of carcinogenesis. It has been proven that RNAi can be used for blocking the factors connected with angiogenesis (vascular endothelial growth factor [VEGF] or angiogenin) in prostate cancer [19], molecules connected with cell adhesion (epithelial cell adhesion molecule [EpCAM]) in breast cancer [20] or factors connected with extracellular matrix degradation, i.e. matrix metalloproteinases (MMPs) [21]. MMPs are a large family of zinc-dependent endopeptidases involved in many physiological and pathological processes. They are responsible for the degradation of extracellular matrix (ECM) components and tissue remodeling. Among the MMPs, we can distinguish a group of gelatinases which include gelatinase A (MMP-2) and gelatinase B (MMP-9). These enzymes have the ability to degrade, among other things, type IV collagen, which is a major structural component of basement membranes. It has been found that the metastatic potential of cancer cells is strongly correlated with gelatinase activity. Elevated expression of MMP-2 and MMP-9 is observed in several types of human cancers. As a consequence gelatinases are often considered as promising therapeutic targets for cancer treatment [22-24].

In our experiment, we suppressed expression of the NANOG gene using the RNAi method and investigated how this process would influence the malignant phenotype of T24 human urinary bladder cells. In particular, we focused on cells' chemoinvasion and migration as aspects of metastasis in vitro, which is thought to be connected with high activity of MMP-2 and MMP-9. The connection between NANOG overexpression and high activity of MMP-2 and/or MMP-9 has been found in the choriocarcinoma JEG-3 cell line [12] and in nasopharyngeal carcinoma [25]. The further purpose of the present study was to investigate the connection between NANOG, MMPs and their tissue inhibitor TIMP-1 (tissue inhibitor of metalloproteinases 1) at both the RNA and protein level.

\section{Material and methods}

\section{Cell culture}

The human urinary bladder cancer cell line T24 (HTB-4) was purchased from ATCC. Cells were cul- 
tivated in RPMI 1640 medium (Life Technologies, Gibco) with $10 \%$ FBS (fetal bovine serum) (Life Technologies, Gibco) and gentamycin (Life Technologies, Gibco) in the concentration of $10 \mu \mathrm{g} / \mathrm{ml}$, under standard conditions at $37^{\circ} \mathrm{C}$ in a humidified atmosphere containing $5 \% \mathrm{CO}_{2}$. Cells were further used for the individual studies. Three independent experiments for each scientific evaluation were run in triplicate for all analyzed samples.

\section{shRNA design and transfection of cancer cells}

The shRNA construction used to silence expression of the NANOG gene was designed using the SIRNA application of EMBOSS. Forward and reverse oligonucleotides of shRNA were annealed and cloned into the pSUPER.neo vector (Oligoengine) according to the manufacturer's procedure. Cells were plated at an initial density of $6 \times 10^{4}$ cells per well in $1000 \mu \mathrm{l}$ of culture medium on a 12-well plate and incubated overnight. Transfection with shRNA silencing the NANOG gene was performed using Lipofectamine 2000 (Invitrogen). $1 \mu \mathrm{g}$ of DNA and $2 \mu \mathrm{l}$ of Lipofectamine were conducted according to the manufacturer's protocol. Transfected cells were incubated for $5 \mathrm{~h}$ in $500 \mu \mathrm{l}$ of Opti-MEM medium (Sigma). After this time, Opti-MEM medium was replaced by standard culture medium. Control groups consisted of non-transfected cells and cells transfected with a scrambled construction (SCR) with a nonsense sequence. In order to evaluate the efficiency of transfection, a construct expressing green fluorescent protein (GFP) was used.

\section{Quantitative reverse transcription polymerase chain reaction (qRTPCR)}

Total RNA was isolated from cells using GeneMATRIX Universal RNA Purification Kit (EURx).
Isolated RNA was quantified using BioPhotometer (Eppendorf). qRTPCR was performed using Brilliant II SYBR Green QRT-PCR Master Mix Kit (Agilent Technologies). qRT PCR normalization was conducted using glyceraldehyde 3-phosphate dehydrogenase (GAPDH) as an endogenous control. qRTPCR reactions were performed on an Mx-300 PCR cycler (Stratagene) for 40 cycles. The thermal profile for the $P C R$ reaction was as follows: $50^{\circ} \mathrm{C}$ for $30 \mathrm{~min}$ (reverse transcription); $95^{\circ} \mathrm{C}$ for $15 \mathrm{~min}$ (initial denaturation); $94^{\circ} \mathrm{C}$ for $15 \mathrm{~s}$ (denaturation), $60^{\circ} \mathrm{C}$ for $1 \mathrm{~min}$ (annealing), $72^{\circ} \mathrm{C}$ for $30 \mathrm{~s}$ (elongation); $72^{\circ} \mathrm{C}$ for $10 \mathrm{~min}$ (final elongation). The primer sequences used in the experiment are presented in Table I. The specificity of qRT PCR reaction was confirmed by melting curve analysis and by the use of electrophoresis on 1.2\% agarose gels, stained with Gel Red fluorescent dye (Biotium). The relative gene expression was calculated using comparative $2\left(^{-\Delta \Delta c t}\right)$ [26] and with Mx3000p software (version 2.0).

\section{Wound-healing assay}

In order to observe the changes in the level of migration and invasion of transfected cancer cells, a wound-healing assay experiment was conducted. Twenty-four hours after transfection, the confluent cell monolayer was wound along and across the plate well using a pipette tip. Digital documentation was collected using an OLYMPUS BX-60 fluorescent microscope with BX-FLA fluorescent accession and DP50 digital camera: directly $\left(\mathrm{T}_{0}\right), 24 \mathrm{~h}\left(\mathrm{~T}_{24}\right)$ and $48 \mathrm{~h}\left(\mathrm{~T}_{48}\right)$ after making the wound. Data were analyzed using NIS-Elements AR software.

\section{Matrigel invasion assay}

Cell invasion was performed using 12-well plates with $8 \mu \mathrm{m}$ pore inserts. Twenty-four hours

Table I. Characteristics of primers used for amplification of target mRNA

\begin{tabular}{|c|c|c|c|c|}
\hline Primer name & Sequence $\left(5^{\prime}-3^{\prime}\right)$ & Length [bp] & Product size [bp] & Reference \\
\hline GAPDH F & GAAGGTGAAGGTCGGAGTC & 19 & \multirow[t]{2}{*}{226} & \multirow{2}{*}{$\begin{array}{l}\text { Commercially } \\
\text { available kit }\end{array}$} \\
\hline GAPDH R & GAAGATGGTGATGGGATTTC & 20 & & \\
\hline NANOG F & CCATCCTTGCAAATGTCTTCTG & 22 & \multirow[t]{2}{*}{115} & \multirow[t]{2}{*}[12]{} \\
\hline NANOG R & CTTTGGGACTGGTGGAAGAATC & 22 & & \\
\hline TIMP-1 F & CTTCCACAGGTCCCACAACC & 20 & \multirow[t]{2}{*}{304} & \multirow[t]{2}{*}[27]{} \\
\hline TIMP-1 R & CAGCCCTGGCTCCCGAGGC & 19 & & \\
\hline MMP-2 F & CAGGGAGCGCTACGATGGAG & 20 & \multirow[t]{2}{*}{202} & \multirow{4}{*}[28]{} \\
\hline MMP-2 R & TCCTTGGGGCAGCCATAGAA & 20 & & \\
\hline MMP-9 F & GCTCACCTTCACTCGCGTG & 19 & \multirow[t]{2}{*}{60} & \\
\hline MMP-9 R & CGCGACACCAAACTGGATG & 19 & & \\
\hline
\end{tabular}


after transfection, $25 \times 10^{3}$ of T24 cells were cultured in a serum-free RPMI-1640 medium in an insert including Matrigel (BD). Inserts were placed in the particular wells of the culture plate containing RPMI-1640 medium with $10 \%$ FBS as a chemoattractant. After the next $24 \mathrm{~h}$, cells were fixed with $4 \%$ paraformaldehyde (PFA) and stained with $0.1 \%$ crystal violet. The number of cells which invaded across the membrane and those which migrated into the bottom of the plate were counted. The digital documentation was collected using a Zeiss Axiovert 40 CFL fluorescent microscope. The images were analyzed using AxioVision Documentation software (version 4.7.1).

\section{Enzyme-linked immunosorbent assay}

The changes in expression of the genes MMP-2, MMP-9 and TIMP-1 were evaluated using enzyme-linked immunosorbent assay (ELISA). Supernatants from bladder cancer cells were collected 24 and $48 \mathrm{~h}$ after the transfection. The experiment was conducted using individual Human ELISA Kits (Abcam) according to the manufacturer's protocols. The absorbance was read at $450 \mathrm{~nm}$ using a TRIAD reader (Dynex Technologies) and data were analyzed with the application of commercially available software on the elisaanalysis. com website [29].

\section{Statistical analysis}

The obtained results were analyzed using a one-way ANOVA: distribution of results was tested using the Shapiro-Wilk test and homogeneity of variance using the Brown-Forsyth test. If the analysis of variance showed a statistically significant difference, it was followed by an LSD (Fisher's least significant difference) for GRT PCR analysis and ELISA analysis or Tukey's HSD (honest signifi-

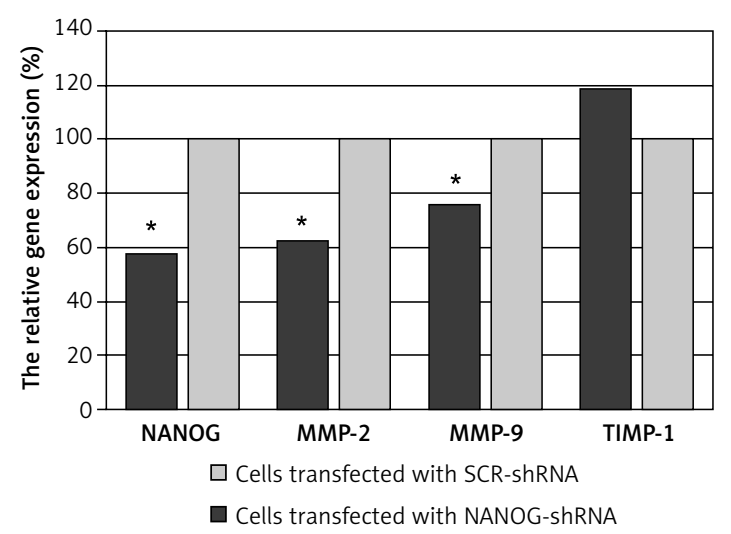

Figure 1. GRT PCR analysis of the relative expression [\%] of NANOG and other genes connected with malignant phenotype in T24 cells transfected with NANOG-shRNA or SCR shRNA. Total RNA was collected $48 \mathrm{~h}$ after cell transfection. Data were obtained from the comparative $2(-\Delta \Delta c t)$ method $\left({ }^{*} p<0.05\right)$ cant difference) post hoc tests for wound-healing and Matrigel invasion assays. Every analysis with a $p<0.05$ was considered as significant. Analyses were performed using Statistica 8 PL software for Windows (StatSoft, Poland).

\section{Results}

shRNA targeting NANOG gene modulates the expression of genes connected with malignant phenotype of cancer cells

In order to evaluate the changes in the expression of examined genes, qRTPCR was performed. Using RNA interference, we knocked down NANOG gene expression in the T24 cells. At $48 \mathrm{~h}$ after transfection, expression of the NANOG gene had decreased to the level of $58 \%$ according to the SCR control ( $p=0.018)$. Down-regulation of NANOG was connected with a decrease in expression of the MMP-2 and MMP-9 genes. At $48 \mathrm{~h}$ after transfection, expression of the $M M P-2$ and MMP-9 genes was reduced to the level of respectively $62.4 \%$ and $76 \%$ according to the SCR control (respectively $p=0.02$ and $p=0.044$ ). We did not observe any statistically significant differences in the expression level of the TIMP-1 gene in cells with modulated NANOG expression ( $p=0.58$ ). The relative expression of individual genes $48 \mathrm{~h}$ after transfection is presented in Figure 1.

\section{Down-regulation of NANOG gene results in} a decrease of cell migration and invasion

In order to evaluate the changes in T24 cell invasion after the down-regulation of NANOG, the Matrigel invasion assay was performed. Preliminary analysis of results showed the changes in the number of cells which invaded within the Matrigel membrane between the examined and control groups. Detailed data analysis showed statistically significant changes in the number of T24 cells with modulated NANOG expression which invaded the outer side of the insert's membrane compared to control/SCR cells $(p=0.02)$. Also the smaller number of cells with modulated NANOG expression migrated to the particular well of the plate containing medium with chemoattractant. However, no statistically significant changes were observed. There were no statistically significant differences between control groups (non-transfected and SCR transfected), either for cells that invaded the outer side of the insert's membrane or to the bottom of a particular well (respectively $p=0.41$ and $p=$ 0.33 ). Data analysis from the Matrigel invasion assay are shown in Figure 2. Photographic documentation from the conducted experiment is shown in Figure 3.

The wound-healing assay experiment indicated NANOG gene involvement in the migration abilities 
A

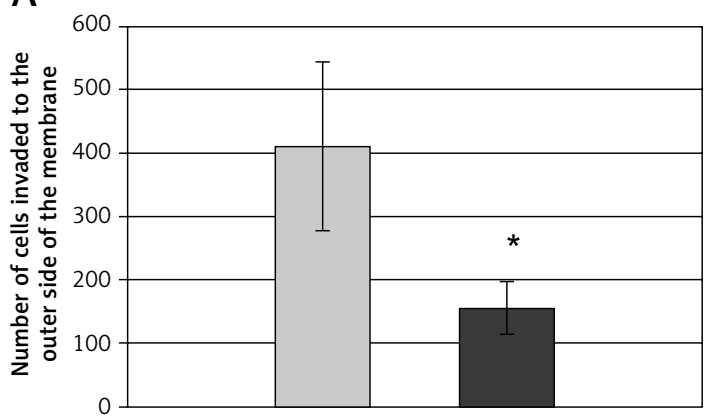

B

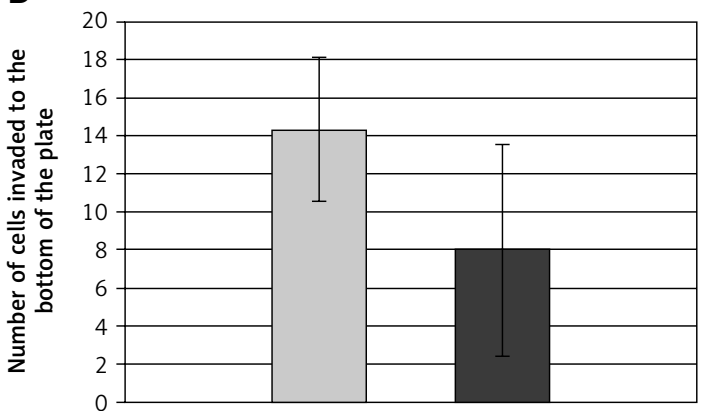

$\square$ Cells transfected with SCR-shRNA

$\square$ Cells transfected with NANOG-shRNA

Figure 2. Matrigel Invasion Assay. Data are expressed as the total number of T24 cells transfected with SCR-shRNA or NANOG-shRNA, which invaded the outer side of the membrane $(\mathbf{A})$ or to the bottom of the plate (B). Four fields were counted per well, $n=2\left({ }^{*} p<0.05\right)$
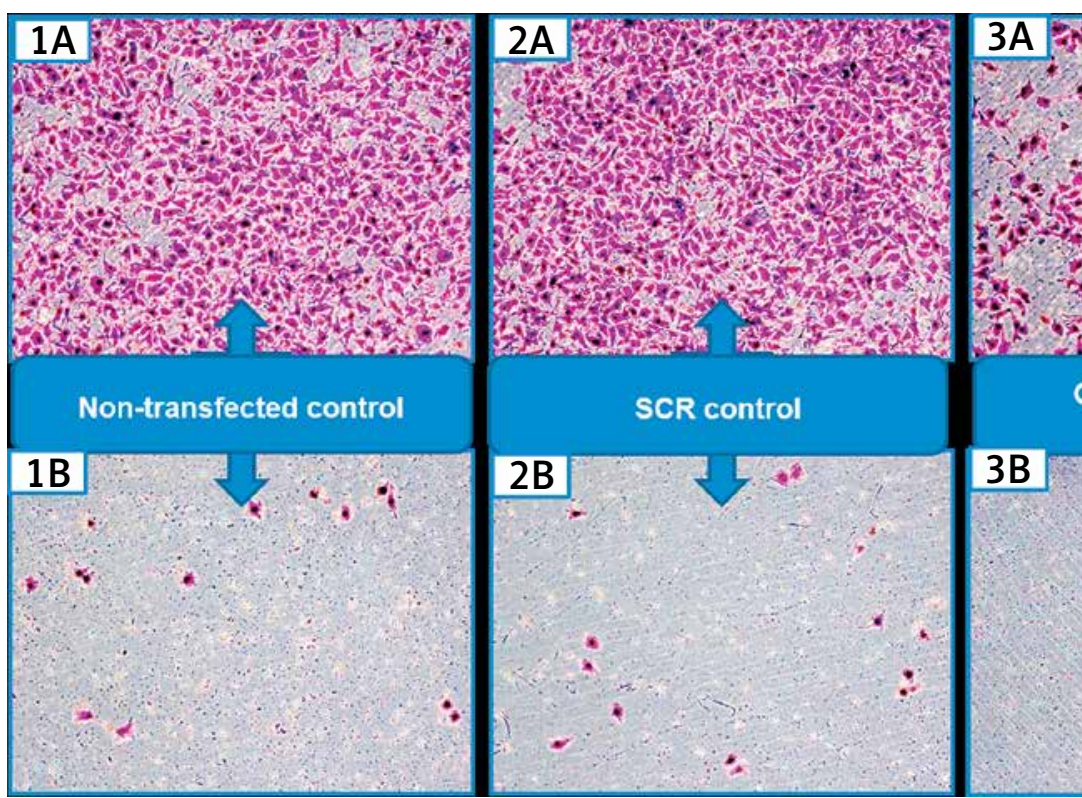

Figure 3. The T24 cells in the experiment using Matrigel invasion chambers. Arabic numbers correspond to the following control/experimental groups: 1 - control group: non-transfected cells; 2 - control group: cells transfected with SCR sequence; 3 - experimental group: cells with modulated expression of NANOG gene. The letters are as follows: A - cells which invaded the outer side of the insert's membrane; B - cells which left the insert within the membrane and invaded the particular well of the plate containing medium with chemoattractant. Cells were solidified and stained $48 \mathrm{~h}$ after transfection (magnification 100x)

of T24 cells. In the control culture (non-transfected cells), $24 \mathrm{~h}$ after making the wound, its width decreased to the level of $11 \%$ of the output value. At $48 \mathrm{~h}$ after making the wound, it was completely filled with migrated cells. In the second control culture (cells transfected with SCR sequence), $24 \mathrm{~h}$ after making the wound, its width decreased to the level of $9 \%$ of the output value. At $48 \mathrm{~h}$ after making the wound, it was almost completely filled with migrated cells. In the experimental culture (cells with modulated NANOG gene expression), $24 \mathrm{~h}$ after making the wound, its width decreased to the level of $27 \%$ of output width. At $48 \mathrm{~h}$ after making the wound, this value remained at a simi- lar level. There were statistically significant differences between the average wound width in experimental groups and between both control groups (both $p<0.05$ ). Photographic documentation from the conducted experiment is shown in Figure 4.

\section{Inhibition of NANOG gene decreases the protein level of MMP-9}

Based on absorbance measurements of MMP-9 protein standards and on the absorbance of control and examined samples, the protein level of MMP-9 was determined. In the samples collected $24 \mathrm{~h}$ after transfection, no statistically signif- 

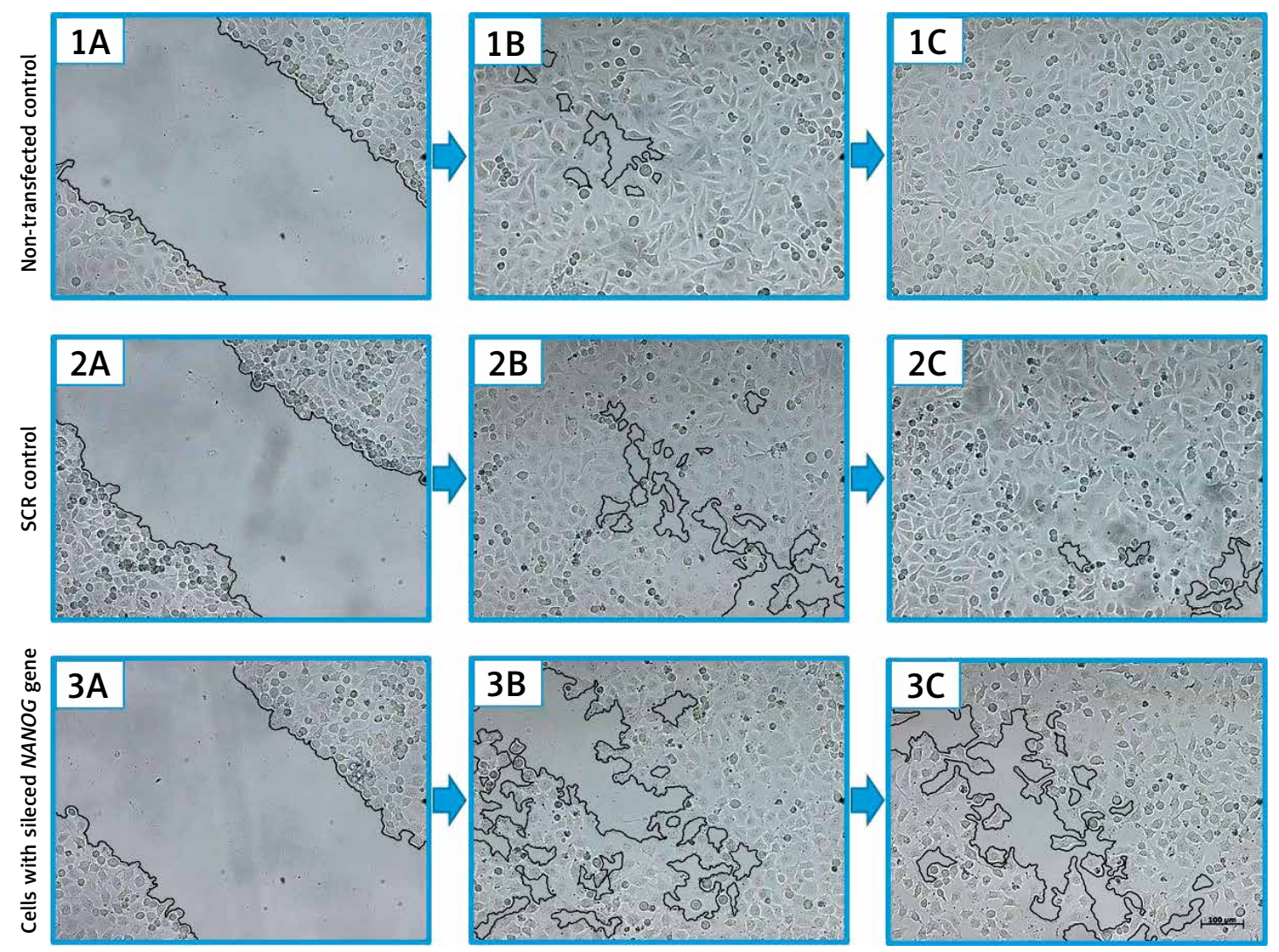

Figure 4. T24 cells in the wound-healing assay. Arabic numbers correspond to the following control/experimental groups: 1 - control group: non-transfected cells; $\mathbf{2}$ - control group: cells transfected with SCR sequence; $\mathbf{3}$ - experimental group: cells with modulated expression of NANOG gene. Letters correspond to the following periods of time: A - T24 cells directly after making the wound (T0); B - T24 cells 24 h after making the wound (T24); C - T24 cells $48 \mathrm{~h}$ after making the wound (T48) (magnification 100×)

icant differences were observed between the level of MMP-9 protein in the control/SCR samples and samples collected from cells with modulated NANOG expression $(p=0.49)$. In the samples collected $48 \mathrm{~h}$ after transfection, a statistically significant decrease of MMP-9 protein level in the examined samples was observed $(p=0.045)$ compared to the control samples. We did not observe

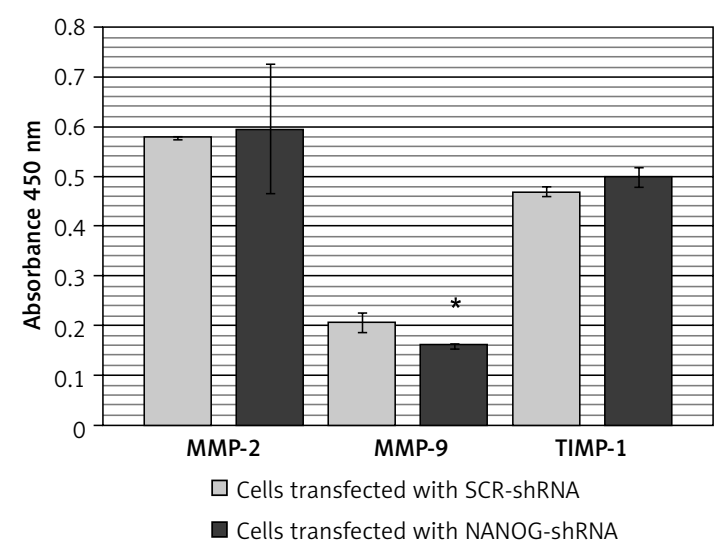

Figure 5. Mean absorbance values for particular protein (MMP-2, MMP-9, TIMP-1) in samples collected from T24 cells transfected with SCR-shRNA and NANOG-shRNA. Samples were collected $48 \mathrm{~h}$ after transfection $\left({ }^{*} p<0.05\right)$ any impact of NANOG inhibition on either MMP-2 or TIMP-1 protein level, in samples collected at either 24 or $48 \mathrm{~h}$ after transfection. Data analysis from the ELISA experiment is shown in Figure 5.

\section{Discussion}

The formation of metastasis is a process, which requires the reduction of cell-cell interaction. As a result, it causes the migration of cells through the extracellular matrix. The process requires changes in cell phenotypes, including reorganization of the cytoskeleton [30].

Cancer stem cells are self-renewing malignant progenitors which are responsible for cancer tumorigenicity, chemoresistance and metastasis. The ECs and CSCs have some common phenotypic properties. Both types of cells are characterized by intensive growth and high expression of telomerase, which is responsible for cell immortality. Trophoblastic cells and cancer cells are also able to infiltrate the local tissues. NANOG is a marker of stem cells that is highly expressed in embryonic stem cells and regulates differentiation, proliferation and division. Years of investigations show that the NANOG gene and its isoforms, together with OCT4 and SOX2, play an important role in 
the development of malignant phenotype of cells. However, abnormal expression of NANOG is found not only in malignant germ cell tumors such as embryonic carcinomas, but also in solid tumors, such as breast cancer, cervical cancer or bladder cancer, including the T24 bladder cancer cell line $[13,17,31-33]$. Cancer stem cells with high metastatic potential usually show epithelial-mesenchymal transition (EMT) markers. This phenomenon is defined by the loss of epithelial morphology and attainment of mesenchymal phenotype. As a result, epithelial cells are transformed into cells which are characterized by high migration and invasiveness potential. Loss of E-cadherin (mostly expressed by epithelial cells) and increasing expression of $\mathrm{N}$-cadherin (mostly expressed by mesenchymal cells) are a major mark of EMT. It has been shown that NANOG can enhance cell invasion by inducing the EMT phenomenon. NANOG is able to decrease the E-cadherin level through SNAIL1 [34] and SNAIL2 transcriptional factors [35-37], which are also connected with an increase of MMP-2 level [36].

In our experiment we found that silencing the NANOG gene in T24 cells, using RNAi, leads to the inhibition of MMP-2 and MMP-9 expression at the transcriptional level, which in the case of MMP-9 is also visible at the protein level. Siu et al. performed a wound-healing assay examination which showed that knocking down NANOG in a choriocarcinoma cell line (JEG-3) leads to slower migration and invasion of cancer cells. Furthermore, the GRTPCR examination showed significant inhibition of MMP-2 and MMP-9 gene expression in JEG-3 cells with silenced expression of the NANOG gene. It has been found that promoters for MMP-2 and MMP-9 genes had been occupied by NANOG in embryonic stem cells. These data suggest that NANOG might affect both MMPs directly [12]. Zhan et al. examined the role of orphan nuclear receptor TR3 in metastasis and proliferation of gastric cancer stem cells (GCSCs). They observed a decrease in the expression of both NANOG and MMP-9 genes after knocking down the TR3 gene in GCSCs [38]. The connection between NANOG and MMP-9 was also observed by Lee et al., who examined the role of $\mathrm{CXCL}_{12}$ / $\mathrm{CXCR}_{4}$ in the tumorigenicity potential of glioblastoma stem-like cells (GSC). Silencing $\mathrm{CXCR}_{4}$ in the glioblastoma $R G_{2}$ cell line using $\operatorname{shrCXCR_{4}}$ reduced the expression of NANOG, MMP-2 and MMP-9 genes [39]. Also Kim et al. reported that silencing of the zinc finger protein 756 (ZNF756) gene in H460 non-small-cell lung carcinoma (NSCLC) led to suppression of NANOG and three MMP genes (MMP-1, MMP-2 and MMP-9) [40]. Imai et al. found a correlation between NANOG expression and malignant phenotype of hypopharyngeal cancer cells (HPC). These cells, which express the transmembrane protein CD271 $\left(\mathrm{CD} 271^{+}\right)$, are also high NANOG expressers. They were characterized by self-renewal, tumor initiating potential and metastatic potential, as they expressed high levels of MMP-1, MMP-2 and MMP-10 [41]. Although relatively little information is available, all these data show that NANOG, MMP-2 and MMP-9 pathways are connected with the development of malignant phenotype of cancer cells. In our work, no such connection was found between NANOG and TIMP-1 expression.

In our experiment, silencing the NANOG gene led to inhibition of T24 cell migration in the wound-healing assay and decreased the invasion level in the Matrigel invasion assay. In the wound-healing examination performed by Borrull et al., A375 cells transfected with a vector encoding the NANOG gene (A375 NANOG) completely filled the wound within $30 \mathrm{~h}$, in contrast to $A 375$ cells containing an empty vector (A375 EV). In the Transwell migration assay, a 3.2-fold increase of A375 NANOG cell transmigration was observed compared to A375 EV control cells [42]. Dang et al. reported that down-regulation of the SNAIL 1 gene decreases the expression of NANOG in the hepatocellular carcinoma (HCC) cell line MHCC97-L. After silencing the SNAIL 1 gene using Snail1-siRNA, MHCC97-L cells migrated more slowly according to control cells transfected with scrambled-siRNA in the wound-healing assay [34]. Niu et al. found the connection between overexpression of miR134 and down-regulation of NANOG mRNA and protein in glioblastoma cell line U87. The results of the Matrigel transwell assay showed that U87 cells with up-regulated miR-134 (and therefore down-regulated NANOG gene) migrated more slowly compared to control cells. High expression of miR-134 in U87 cells also inhibited the speed of wound closure compared to control cells in the wound-healing/scraping assay [43]. Latifi et al. examined the EMT and CSCs phenotype of the ovarian cancer cell line OVCA 433 in response to cisplatin in vitro. In the qRT-PCR experiment, enhanced expression of the NANOG gene was observed in response to cisplatin in OVCA 433 cells. Cisplatin also enhanced MMP-2 and MMP-9 expression at both the mRNA and protein level. Enhanced expression of two MMPs was connected with enhanced migratory abilities shown in the wound-healing assay [44].

In conclusion, the results of this study indicate that down-regulation of the NANOG gene is connected with a decrease of T24 cell migration and invasion in vitro. The changes of the malignant phenotype of bladder cancer cells, including the decrease of cell migration and invasion, might be connected with down-regulation of MMP-2 and 
MMP-9 genes. This connection was not observed in the case of the TIMP-1 gene. The lack of changes in the protein level of MMP-2 in the ELISA experiment is striking. This phenomenon needs further examination.

\section{Acknowledgments}

This work was supported by grants KNW1-050/D/1/0, KNW-1-035/D/2/0, KNW-2-004/ D/3/N, KNW-2-010/D/3/N, KNW-1-095/N/3/0 and KNW-1-110/P/2/0 funded by the Medical University of Silesia, Katowice, Poland. The first author participates in "DoktoRIS - scholarship program for innovative Silesia", co-financed by the European Union under the European Social Fund.

The authors wish to thank the Department of Instrumental Analysis of the Medical University of Silesia for providing the TRIAD fluorescence reader.

\section{Conflict of interest}

The authors declare no conflict of interest.

\section{References}

1. Wojciechowska U, Didkowska J, Zatoński W. Cancer in Poland in 2010. Ministry of Heath, Warsaw 2012; 2021, 23.

2. Wojtyś P, Godlewski D, Antczak A. Predictions of cancer incidence in Poland in 2019. Cent Eur J Med 2013; 8: 185-91.

3. Clarke MF, Dick JE, Dirks PB, et al. Cancer stem cells: perspectives on current status and future directions: AACR Workshop on cancer stem cells. Cancer Res 2006; 66: 9339-44.

4. Bernstein A. Cancer stem cells: the centrality of translational research to cancer control. CMAJ 2007; 176: 29-30.

5. Liu A, Yu X, Liu S. Pluripotency transcription factors and cancer stem cells: small genes make a big difference. Chin J Cancer 2013; 32: 483-7.

6. Theunissen TW, Silva JC. Switching on pluripotency: a perspective on the biological requirement of Nanog. Philos Trans R Soc Lond B Biol Sci 2011; 366: 2222-9.

7. Gauchat D, Mazet F, Berney C, et al. Evolution of Antpclass genes and differential expression of Hydra Hox/ paraHox genes in anterior patterning. Proc Natl Acad Sci U S A 2000; 97: 4493-8.

8. Chang DF, Tsai SC, Xing CW, Ping X, Senadheera D, Lutzko C. Molecular characterization of the Human Nanog protein. Stem Cells 2009; 27: 812-21.

9. Ambady S, Malcuit C, Kashpur O, et al. Expression of NANOG and NANOGP8 in a variety of undifferentiated and differentiated human cells. Int J Dev Biol 2010; 54: 1743-54.

10. Booth HA, Holland PW. Eleven daughters of Nanog. Genomics 2004; 84: 229-38.

11. Fairbanks DJ, Maughan PJ. Evolution of the NANOG pseudogene family in the human and chimpanzee genomes. BMC Evol Biol 2006; 6: 12.

12. Siu MK, Wong ES, Chan HY, Ngan HY, Chan KY, Cheung AN. Overexpression of NANOG in gestational trophoblastic diseases: effect on apoptosis, cell invasion, and clinical outcome. Am J Pathol 2008; 173: 1165-72.
13. Jeter CR, Badeaux M, Choy G, et al. Functional evidence that the self-renewal gene NANOG regulates human tumor development. Stem Cells 2009; 27: 993-1005.

14. Zhang J, Wang X, Li M, Han J, Chen B. NANOGP8 is a retrogene expressed in cancers. FEBS J 2006; 273: 1723-30.

15. Hepburn AC, Veeratterapillay R, Williamson SC, et al. Side population in human non-muscle invasive bladder cancer enriches for cancer stem cells that are maintained by MAPK signalling. PLoS One 2012; 7: e50690.

16. Ben-Porath I, Thomson MW, Carey VJ, et al. An embryonic stem cell-like gene expression signature in poorly differentiated aggressive human tumors. Nat Genet 2008; 40: 499-507.

17. Ojha R, Jha V, Singh SK, Bhattacharyya S. Autophagy inhibition suppresses the tumorigenic potential of cancer stem cell enriched side population in bladder cancer. Biochim Biophys Acta 2014; 1842: 2073-86.

18. Morgan G, Ward R, Barton M. The contribution of cytotoxic chemotherapy to 5-year survival in adult malignancies. Clin Oncol (R Coll Radiol) 2004; 16: 549-60.

19. Takei Y, Kadomatsu K, Yuzawa Y, Matsuo S, Muramatsu T. A small interfering RNA targeting vascular endothelial growth factor as cancer therapeutics. Cancer Res 2004; 64: 3365-70.

20. Osta WA, Chen Y, Mikhitarian K, et al. EpCAM is overexpressed in breast cancer and is a potential target for breast cancer gene therapy. Cancer Res 2004; 64: 5818-24.

21. Salvi A, Arici B, De Petro G, Barlati S. Small interfering RNA urokinase silencing inhibits invasion and migration of human hepatocellular carcinoma cells. Mol Cancer Ther 2004; 3: 671-8.

22. Verma RP, Hansch C. Matrix metalloproteinases (MMPs): chemical-biological functions and (Q)SARs. Bioorg Med Chem 2007; 15: 2223-68.

23. Artacho-Cordón F, Ríos-Arrabal S, Lara PC, ArtachoCordón A, Calvente I, Núñez MI. Matrix metalloproteinases: potential therapy to prevent the development of second malignancies after breast radiotherapy. Surg Oncol 2012; 21: e143-51.

24. Fink K, Boratyński J. Rola metaloproteinaz w modyfikacji macierzy zewnątrzkomórkowej w nowotworowym wzroście inwazyjnym, w przerzutowaniu i w angiogenezie. Postep Hig Med Dosw 2012; 66: 609-28.

25. Luo W, Yao K. Molecular characterization and clinical implications of spindle cells in nasopharyngeal carcinoma: a novel molecule-morphology model of tumor progression proposed. PLoS One 2013; 8: e83135.

26. Livak KJ, Schmittgen TD. Analysis of relative gene expression data using real-time quantitative PCR and the $\left.2{ }^{-\Delta \Delta C t}\right)$ method. Methods 2001; 4: 402-8.

27. Lamari FN, Zompra AA, Pateraki E, et al. Gonadotropin-releasing hormone analogues alter gene expression of metalloproteinases and their tissue inhibitors in human breast cancer epithelial cells. Anticancer Res 2006; 26: 4615-21.

28. Sypnieweski D, Bednarek I, Gałka S, et al. Ekspresja żelatynaz A i B oraz inwazyjność komórek raka płuc i raka pęcherza moczowego $w$ hodowlach in vitro traktowanych wybranymi tetracyklinami. Farm Przegl Nauk 2009; 8: 17-23.

29. Website: http://elisaanalysis.com/

30. Shan J, Shen J, Liu L et al. Nanog regulates self-renewal of cancer stem cells through the insulin-like growth factor pathway in human hepatocellular carcinoma. Hepatology 2012; 56: 1004-14.

31. Yang L, Zhang X, Zhang $M$, et al. Increased Nanog expression promotes tumor development and Cisplatin re- 
sistance in human esophageal cancer cells. Cell Physiol Biochem 2012; 30: 943-52.

32. Zhu YT, Zhao Z, Fu XY, et al. The granulocyte macrophage-colony stimulating factor surface modified MB49 bladder cancer stem cells vaccine against metastatic bladder cancer. Stem Cell Res 2014; 13: 111-22.

33. Zhang Y, Wang Z, Yu J, et al. Cancer stem-like cells contribute to cisplatin resistance and progression in bladder cancer. Cancer Lett 2012; 322: 70-7.

34. Dang H, Ding W, Emerson D, Rountree CB. Snail1 induces epithelial-to-mesenchymal transition and tumor initiating stem cell characteristics. BMC Cancer 2011; 11: 396.

35. Siu MK, Wong ES, Kong DS, et al. Stem cell transcription factor NANOG controls cell migration and invasion via dysregulation of E-cadherin and FoxJ1 and contributes to adverse clinical outcome in ovarian cancers. Oncogene 2013; 32: 3500-9.

36. Sun C, Sun L, Jiang K et al. NANOG promotes liver cancer cell invasion by inducing epithelial-mesenchymal transition through NODAL/SMAD3 signaling pathway. Int J Biochem Cell Biol 2013; 45: 1099-108.

37. Luo W, Li S, Peng B, Ye Y, Deng X, Yao K. Embryonic stem cells markers SOX2, OCT4 and Nanog expression and their correlations with epithelial-mesenchymal transition in nasopharyngeal carcinoma. PLoS One 2013; 8: e56324.

38. Zhan YY, He JP, Chen HZ, Wang WJ, Cai JC. Orphan receptor TR3 is essential for the maintenance of stem-like properties in gastric cancer cells. Cancer Lett 2013; 329: 37-44

39. Lee CC, Lai JH, Hueng DY, et al. Disrupting the CXCL12/ CXCR4 axis disturbs the characteristics of glioblastoma stem-like cells of rat RG2 glioblastoma. Cancer Cell Int 2013; 13: 85.

40. Kim B, Sohn EJ, Jung JH, et al. Inhibition of ZNF746 suppresses invasion and epithelial to mesenchymal transition in $\mathrm{H} 460$ non-small cell lung cancer cells. Oncol Rep 2013; 31: 73-8.

41. Imai T, Tamai K, Oizumi S, et al. CD271defines a stem cell-like population in hypopharyngeal cancer. PLoS One 2013; 8: e62002.

42. Borrull A, Ghislin S, Deshayes F, et al. Nanog and Oct4 overexpression increases motility and transmigration of melanoma cells. J Cancer Res Clin Oncol 2012; 138 : 1145-54.

43. Niu CS, Yang Y, Cheng CD. MiR-134 regulates the proliferation and invasion of glioblastoma cells by reducing Nanog expression. Int J Oncol 2013; 42: 1533-40.

44. Latifi A, Abubaker K, Castrechini N, et al. Cisplatin treatment of primary and metastatic epithelial ovarian carcinomas generates residual cells with mesenchymal stem cell-like profile. J Cell Biochem 2011; 112: 2850-64. 